\title{
Effect of a nutrient mixture on the localization of extracellular matrix proteins in HeLa human cervical cancer xenografts in female nude mice
}

\author{
M. WAHEED ROOMI, JOHN CHA, TATIANA KALINOVSKY, NUSRATH ROOMI, \\ ALEKSANDRA NIEDZWIECKI and MATTHIAS RATH \\ Dr Rath Research Institute, Santa Clara, CA 95050, USA
}

Received September 6, 2014; Accepted June 11, 2015

DOI: $10.3892 /$ etm.2015.2591

\begin{abstract}
Cervical cancer is one of the most commonly diagnosed cancers and a significant cause of mortality in women worldwide. Although cervical cancer is fully treatable in the early stages, once it has metastasized, patient outcome is poor. The objective of the present study was to investigate the effect of dietary supplementation with a nutrient mixture (NM) containing lysine, ascorbic acid, proline, green tea extract and other micronutrients on the expression of extracellular matrix (ECM) proteins in HeLa cell xenografts in nude female mice. After housing for 1 week, female athymic nude mice between 5 and 6 weeks of age $(n=12)$ were inoculated subcutaneously with $3 \times 10^{6} \mathrm{HeLa}$ cells in phosphate-buffered saline and Matrigel and randomly divided into two groups. These were the control group, in which the mice were fed with regular mouse chow, and the NM group, in which the mice were fed with the regular diet supplemented with $0.5 \% \mathrm{NM}$ $(\mathrm{w} / \mathrm{w})$. After 4 weeks, the tumors were excised and processed for histology. Tumor growth was evaluated and the tumors were stained for the ECM proteins collagen I, collagen IV, fibronectin, laminin, periodic acid-Schiff (PAS) and elastin. NM strongly inhibited (by $59 \%, \mathrm{P}=0.001$ ) the growth of $\mathrm{HeLa}$ xenografts in nude mice. Tumors from control mice exhibited little to no collagen I expression either internally or in the fibrous capsule, while tumors from the NM group expressed collagen $\mathrm{I}$ in the fibrous capsule and within the tumor. Tumors from the control group showed diffuse cytoplasmic and capsular collagen IV with abundant nucleated cells. NM treatment substantially increased collagen IV production and induced a dense fibrous network of collagen IV with chambers
\end{abstract}

Correspondence to: Dr Aleksandra Niedzwiecki, Dr Rath Research Institute, 1260 Memorex Drive, Santa Clara, CA 95050, USA

E-mail: author@drrath.com

Key words: HeLa, nutrient mixture, tumor growth, immunohistochemistry, collagen I, collagen IV, fibronectin, laminin, periodic acid-Schiff, elastin that surrounded live nucleated cells and large amounts of necrotic cell debris. Tumors from the mice fed with the NM exhibited a well-defined border of fibronectin in the capsule and intense areas of staining internally whereas control group tumors showed less overall fibronectin with sporadic internal staining and little in the fibrous capsule. Although laminin appeared abundantly in control and NM-treated tumors, the NM group tumors exhibited a chamber-like network of laminin internally. Tumors from the control group exhibited internal areas of intense PAS staining, whereas tumors from the NM-treated group exhibited a more uniform diffuse pattern of PAS staining. In conclusion, NM supplementation of HeLa xenograft-bearing female nude mice demonstrated a potent inhibition of tumor growth and enhancement of ECM proteins, suggesting the therapeutic value of this specific nutrient complex in the treatment of cervical cancer.

\section{Introduction}

Cervical cancer is the third most commonly diagnosed cancer and the fourth most common cause of mortality in women worldwide (1). In 2014, 12,360 new cases of invasive cervical cancer and $\sim 4,020$ cases of mortality from this disease were estimated for the USA (2). The development of cervical cancer is a slow process; it typically takes 10-15 years for the pre-cancerous condition dysplasia to develop into cancer. Although cervical cancer is fully treatable in the early stages, once it has metastasized, patient outcome is poor (3).

Metastasis occurs following the detachment of cancer cells from the primary tumor. The detached cells invade through degraded basement membrane into the surrounding stroma, enter into the vascular or lymphatic system and are transported to distal sites such as the liver, lungs and brain, where they undergo extravasation, tumor cell proliferation and angiogenesis (4-8). The extracellular matrix (ECM), which comprises collagen, proteoglycans, fibronectin, laminin and other glycoproteins (9-11), acts as a barrier to cancer cell invasion, and tumor cell invasion is dependent upon its degradation. Matrix metalloproteinases (MMPs) and urokinase plasminogen activators (uPA) are also involved in tumor invasion and metastasis. Clinical and experimental studies have indicated that elevated levels of UPA and MMPs are associated with 
tumor growth, cancer progression, metastasis and a reduction in the survival time of patients $(12,13)$. The expression of MMP-9 at the mRNA and protein levels has been shown to be significantly elevated in tumor and stromal cells of invasive squamous cell carcinoma of the uterine cervix (14).

Nutrients such as lysine and ascorbic acid have been suggested to target plasmin-mediated connective tissue degradation as a universal approach to the prevention of tumor growth and expansion (15). Lysine binds to the active sites of plasminogen, thereby blocking the conversion of plasminogen to plasmin and the plasmin-induced MMP activation cascade (16). We have developed a strategy to inhibit the development and spread of cancer using a nutrient mixture (NM) comprising nutrients such as lysine, proline, ascorbic acid and green tea extract. This mixture has exhibited synergistic anticancer activity in vivo and in vitro in a number of cancer cell lines through the inhibition of cancer cell growth, MMP secretion, invasion, metastasis and angiogenesis (17).

In previous studies, NM was found to significantly inhibit HeLa cervical cancer cell proliferation in vitro, MMP-2 and -9 secretion, uPA activity and Matrigel invasion, in addition to enhancing TIMP-2 activity $(18,19)$. In the present study the in vivo effect of NM supplementation on tumor growth and ECM protein markers were investigated in HeLa cervical tumor xenografts in female nude mice. Morphological changes in key ECM proteins associated with the tumor, including collagen I, collagen IV, fibronectin, laminin, periodic acid-Schiff (PAS) and elastin, were evaluated.

\section{Materials and methods}

Animals. Female athymic nude mice, 5 weeks of age, were purchased from Simonsen Laboratories (Gilroy, CA, USA) and maintained in microisolator cages under pathogen-free conditions on a 12-h light/12-h dark schedule for 1 week. All procedures were performed according to guidelines for the humane and customary care and use of experimental animals and followed a protocol prepared by a veterinary consultant of Stanford University (Stanford, CA, USA) and approved by the Animal Safety Review Committee of Dr Rath Research Institute (Santa Clara, CA, USA).

Experimentaldesign. After housing for 1 week, 5- or 6-week-old female athymic nude mice $(n=12)$ were inoculated subcutaneously with $3 \times 10^{6} \mathrm{HeLa}$ cells in $0.2 \mathrm{ml}$ phosphate-buffered saline (PBS) and $0.1 \mathrm{ml}$ Matrigel (BD Biosciences, Bedford, MA, USA). Following the inoculation, the mice were randomly divided into two groups. These were the control group, in which the mice were fed regular Purina mouse chow (Laboratory Rodent Diet 5001; Purina Mills, Richmond, IN, USA), and the NM group, in which the mice were fed the regular diet supplemented with $0.5 \% \mathrm{NM}(\mathrm{w} / \mathrm{w})$. The mice consumed an average of $4 \mathrm{~g}$ diet/day during the study. Thus, the supplemented mice received $20 \mathrm{mg}$ NM per day. After 4 weeks, the mice were anesthetized/sacrificed by exposure to isoflurane USP soaked cotton balls (Piramel Healthcare Ltd., Medak, Ap, India) in a closed environment. The tumors were excised, weighed and processed for histological examination. The mean weight of the mice at the initiation and termination of the study did not differ significantly between the groups.

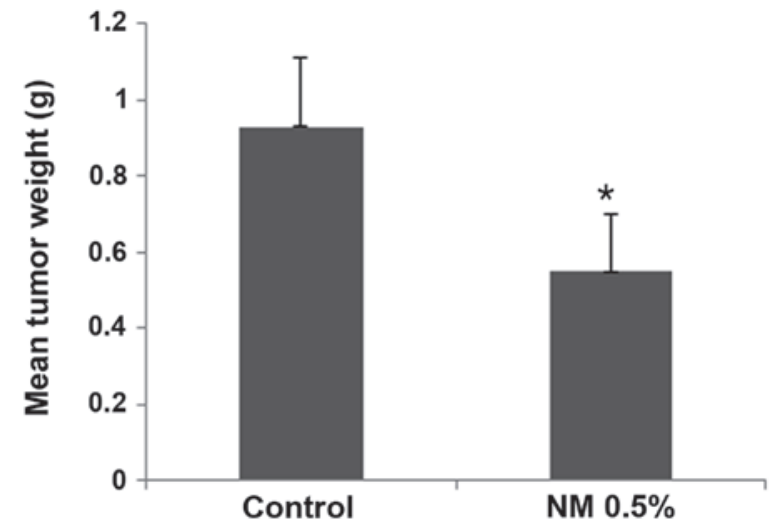

Figure 1. Effect of nutrient mixture (NM) $0.5 \%$ supplementation on HeLa xenograft tumor weight. ${ }^{*} \mathrm{P}=0.001$ vs. control).

Immunohistochemistry. Tumors were placed in a formalin cassette and sent to IDEXX Laboratories, Inc. (Sacramento, CA, USA) and HistoTox Labs, Inc. (Boulder, CO, USA) for analysis. Formalin-fixed samples of tumors were trimmed, processed, blocked, sectioned and stained with hematoxylin and eosin (H\&E) and elastic-Van Gieson stains, and evaluated microscopically by IDEXX Laboratories, Inc. HistoTox Labs, Inc. conducted PAS histochemistry of the tumor sections as well as the immunohistochemical analysis of collagens I and IV, fibronectin, laminin and elastin.

\section{Results}

Tumor growth. NM strongly inhibited the growth of HeLa xenografts in nude mice. In the mice that were fed a diet supplemented with $0.5 \% \mathrm{NM}$, the tumor weight was inhibited by $59 \%(\mathrm{P}=0.001)$ compared with that in the control group mice, as shown in Fig. 1. No significant difference in initial and final mean body weights was observed between the groups.

Histology of the tumors. Histology of the two groups was comparable. However, the fibrous capsule in the NM-treated group was prominent while the tumor border in the untreated group was poorly defined (not shown).

Collagen I. Tumors from control mice exhibited little to no collagen I expression, either internally or in the fibrous capsule, as shown in Fig. 2A and B. By contrast, tumors from the NM-treated mice expressed notably greater expression levels of collagen I in the fibrous capsule and some interdigitation and lamellar structures of collagen I within the tumor (Fig. 2C and D).

Collagen IV. The control tumors demonstrated diffuse cytoplasmic and capsular collagen IV with abundant nucleated cells, as shown in Fig. 3A and B. There was an intense increase in collagen IV production within the tumors of the mice that underwent treatment with NM. NM supplementation induced a dense fibrous network of collagen IV, creating chambers that surrounded live nucleated cells and large amounts of necrotic cell debris, as shown in Fig. 3C and D. The fibrotic network of collagen IV became denser towards the core of the tumor and the increased density of 

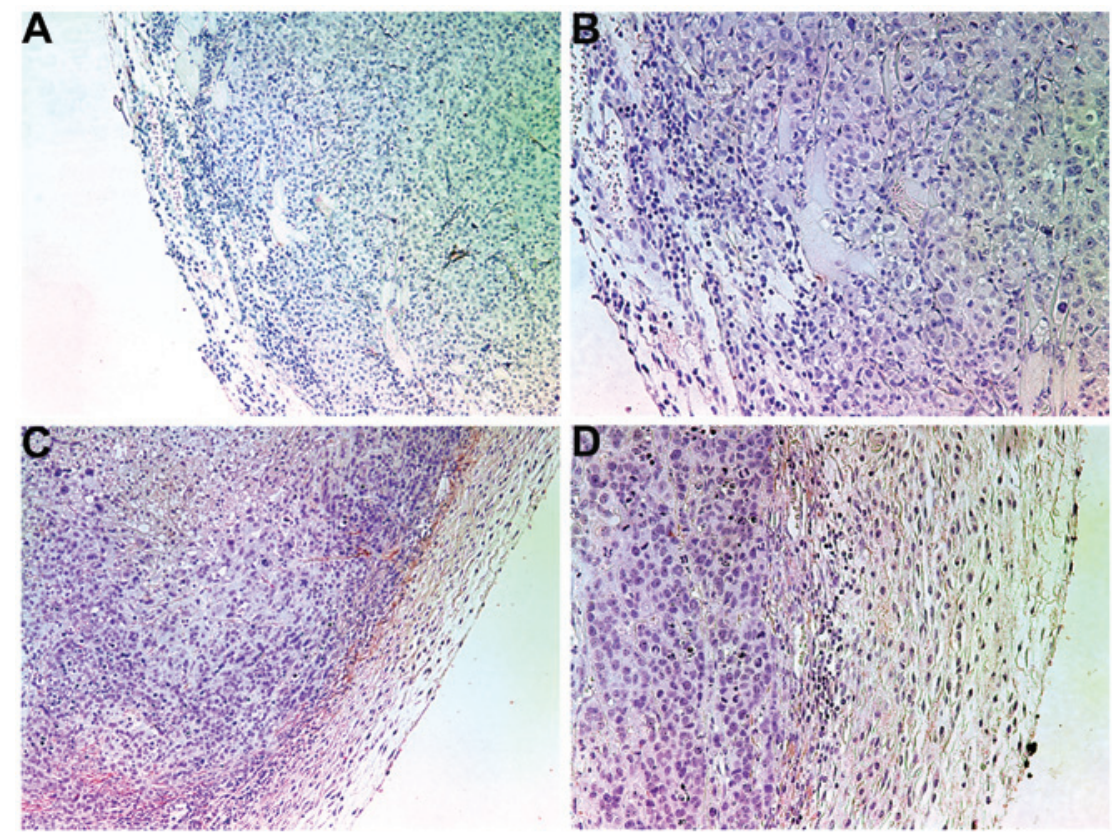

Figure 2. Effect of nutrient mixture (NM) supplementation on collagen I in representative tumors from the control and NM groups. Immunohistochemical staining. (A) Control (magnification, x10); (B) control (magnification, x20); (C) NM (magnification, x10); (D) NM (magnification, x20).
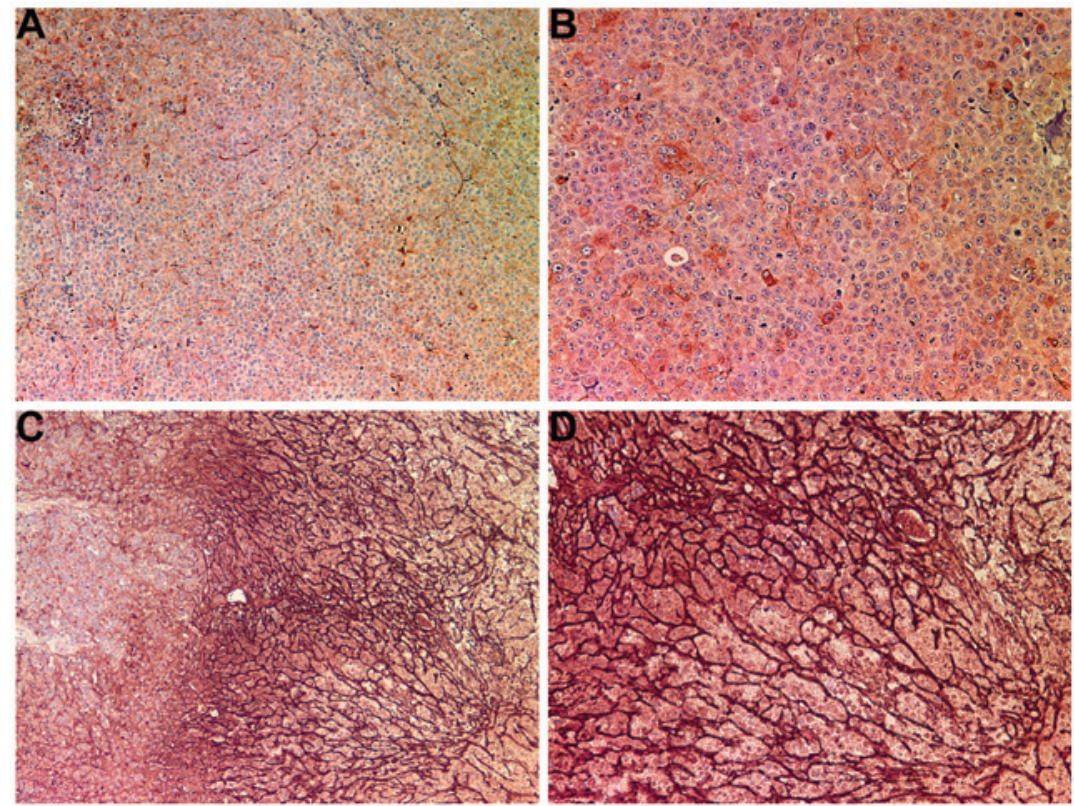

Figure 3. Effect of nutrient mixture (NM) supplementation on collagen IV in representative tumors from the control and NM groups. Immunohistochemical staining. (A) Control (magnification, x10); (B) control (magnification, x20); (C) NM (magnification, x10); (D) NM (magnification, x20).

collagen IV was associated with a greater amount of cell necrosis, as evidenced by a lack of nuclear staining.

Fibronectin. Less fibronectin appeared in the control tumor tissue than in the tumors from the NM-treated mice. Tumors from the control group exhibited intense sporadic internal staining in a heterogeneous interdigitating pattern with very little staining in the fibrous capsule (Fig. 4A and B). Tumors from the NM-treated mice exhibited a well-defined border of fibronectin in the capsule and intense areas of staining internally (Fig. 4C and D).
Laminin. Laminin appeared abundantly in the tumors from the control and NM groups. In the NM group, chamber-like networks of laminin were formed within the tumors (Fig. 5).

$P A S$. Tumors from the control group exhibited internal areas of intense PAS staining (Fig. 6A and B) whereas the tumors from the NM-treated group showed a more uniform and diffuse pattern of PAS staining (Fig. 6C and D).

Elastin. No conclusive difference was observed between the tumors from the control and NM-treated groups (not shown). 

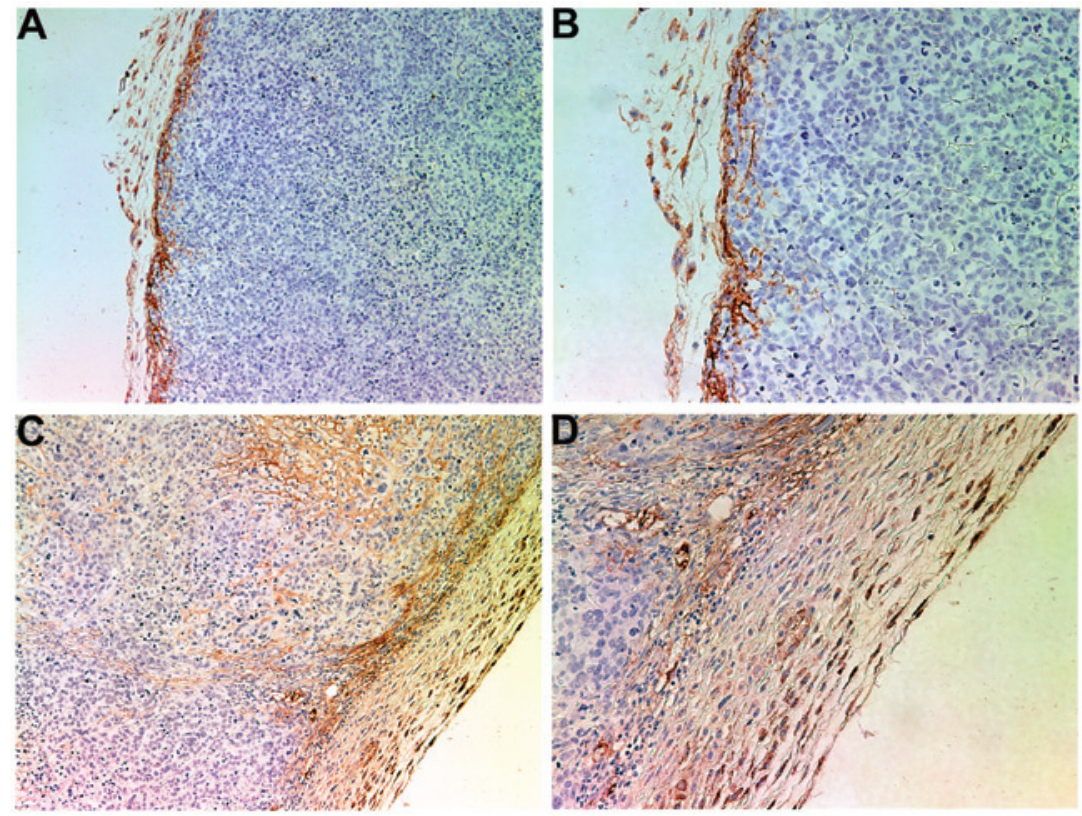

Figure 4. Effect of nutrient mixture (NM) supplementation on fibronectin in representative tumors from the control and NM groups. Immunohistochemical staining. (A) Control (magnification, x10); (B) control (magnification, x20); (C) NM (magnification, x10); (D) NM (magnification, x20).
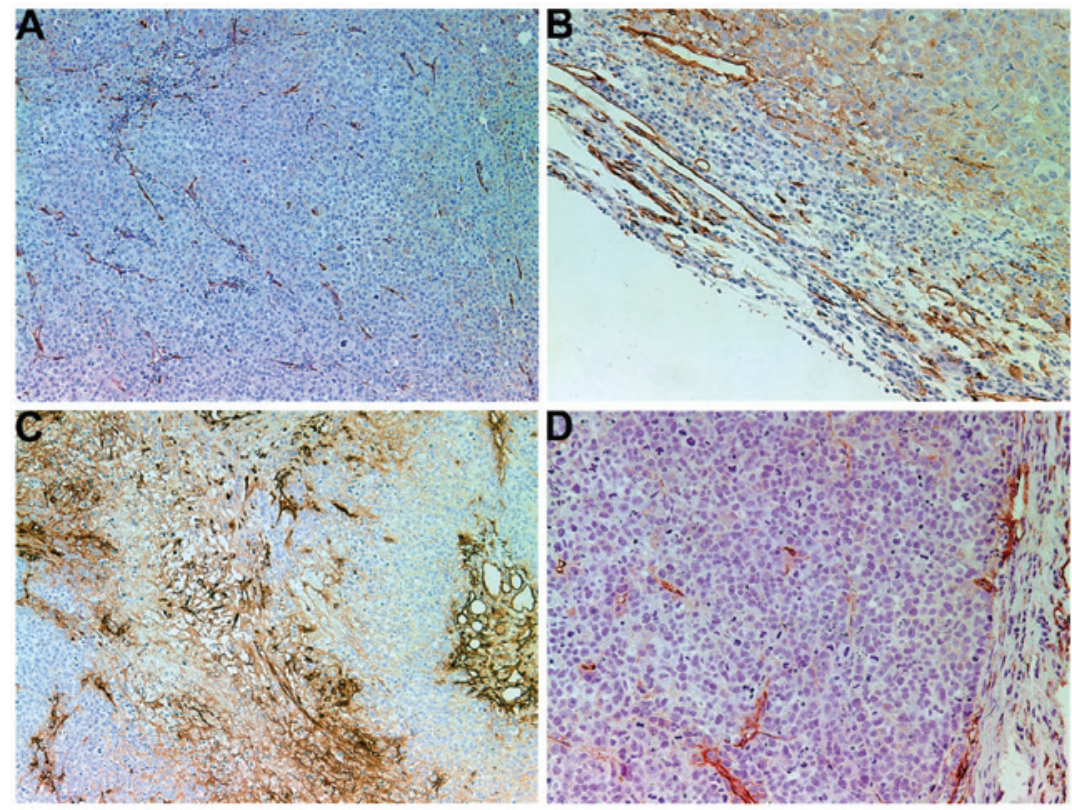

Figure 5. Effect of nutrient mixture (NM) supplementation on laminin in representative tumors from the control and NM groups. Immunohistochemical staining. (A) Control (magnification, x10); (B) control (magnification, x20); (C) NM (magnification, x10); (D) NM (magnification, x20).

\section{Discussion}

Tumor cell invasion is associated with degradation of the ECM, which is intact in normal cells. Among various types of MMP, MMP-2 and MMP-9 are pivotal in tumor cell invasion and metastasis as they degrade type IV collagen, a major component of the ECM (11-13). Barsky et al demonstrated that in invasive tumors the basement membrane, specifically collagen IV and laminin components, was thinned, fragmented and disrupted, while benign and in situ lesions had intact basement membranes with linear staining of collagen IV and laminin (10). Stromal resistance to invasion is dependent upon the encapsulation of the neoplastic cells by a practically impenetrable barrier of dense fibrous tissue $(15,20)$. In the present study, NM supplementation of HeLa xenograft-bearing female nude mice resulted in a significant reduction in mean tumor weight compared with that in the control group. Furthermore, immunohistochemical staining of the tumors confirmed the protective effect of nutrient supplementation on the basement membrane.

Control group tumors showed diffuse cytoplasmic and capsular collagen IV with abundant nucleated cells. In marked contrast, NM supplementation induced intense internal collagen IV production, forming a dense fibrous network of 


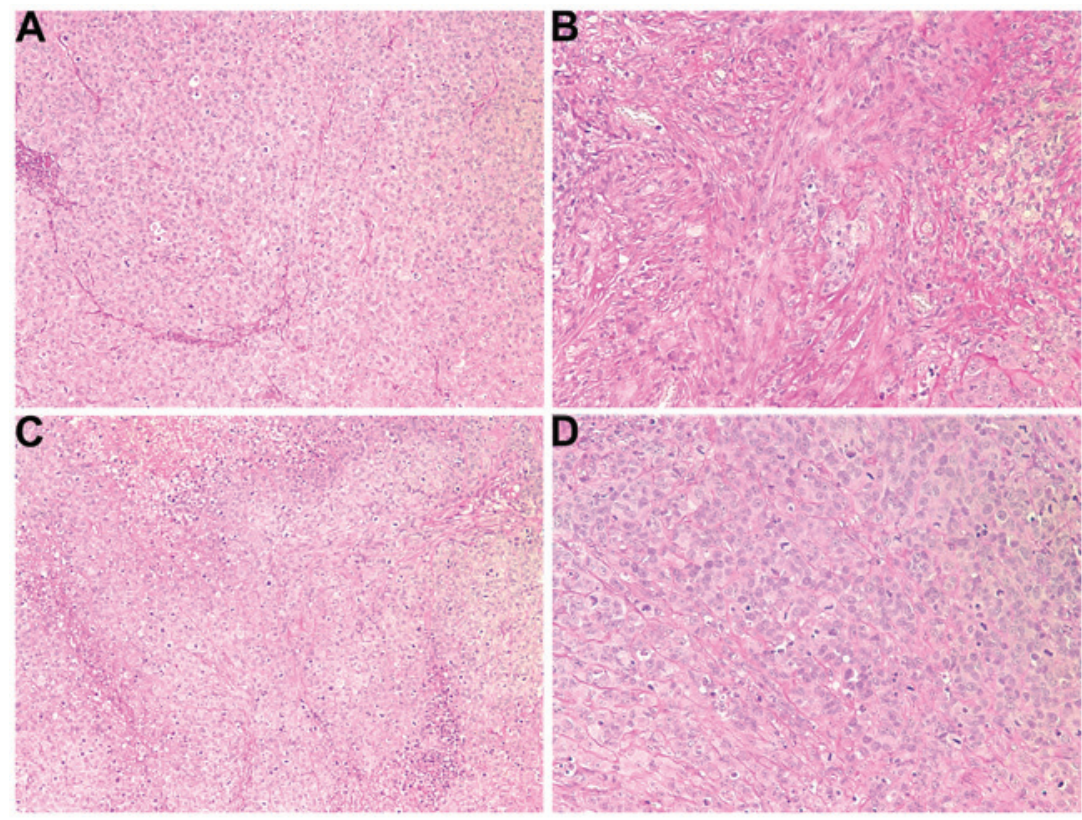

Figure 6. Effect of nutrient mixture (NM) supplementation on periodic acid-Schiff staining in representative tumors from the control and NM groups Histochemical staining. (A) Control (magnification, x10); (B) control (magnification, x20); (C) NM (magnification, x10); (D) NM (magnification, x20).

collagen IV that surrounded live nucleated cells and large amounts of necrotic cellular debris. The fibrotic response observed with NM supplementation is similar to the collagen deposition reported by Almholt et al when investigating an experimental pan-MMP inhibiting drug, which was shown to decrease metastatic burden 100-fold (21). Furthermore, tumors from the control group mice exhibited little to no collagen I expression either internally or in the fibrous capsule. By contrast, tumors from the NM-treated mice expressed greater amounts of collagen I in the fibrous capsule, and some interdigitation and lamellar structures of collagen I were present within the tumor.

Fibronectin, a high molecular weight glycoprotein binds ECM components such as collagen, fibrin and heparin sulfate proteoglycans (22). Fibronectin affects various cellular interactions with the ECM and plays important roles in cell adhesion, migration, growth and differentiation (23). Altered fibronectin expression, degradation and organization have been associated with cancer progression (23). Tumors from NM-treated mice exhibited well-defined borders of fibronectin in the capsule and intense areas of staining internally. By contrast, control tumors showed less fibronectin staining with a sporadic internal pattern and little in the fibrous capsule.

Laminins, major glycoproteins in the basal lamina, influence cell differentiation, migration and adhesion, as well as phenotype and survival (24). In the present study, laminin appeared abundantly in tumors from the two groups. In tumors from the NM-treated mice, chamber-like networks of laminin were formed internally.

Nutrients such as lysine and ascorbic acid have been hypothesized to modulate tumor growth and expansion by inhibiting ECM degradation and MMP activity, and strengthening the integrity of the connective tissue surrounding cancer cells (15). Based on this approach we developed a complex of nutrients that can simultaneously affect key cancer mechanisms through their synergistic effects. The individual components of this mixture have various effects on certain critical aspects of cancer. For optimization of the structure of the ECM, adequate supplies of ascorbic acid and the amino acids lysine and proline are essential to ensure the proper synthesis and hydroxylation of collagen fibers. In addition, lysine contributes to the stability of the ECM as a natural inhibitor of plasmin-induced proteolysis $(15,25)$. Manganese and copper are essential cofactors for collagen formation. Green tea extract has a well-documented ability to modulate cancer cell growth, metastasis, angiogenesis and other aspects of cancer progression (26-30). N-acetyl cysteine and selenium have demonstrated the ability to inhibit the expression of MMP-9 and invasive activities of tumor cells, as well as the migration of endothelial cells through ECM (31-33). Ascorbic acid has demonstrated cytotoxic and antimetastatic actions on malignant cell lines (34-39), and it has been observed that the levels of ascorbic acid in cancer patients are low (40,41). Low levels of arginine, a precursor of nitric oxide (NO), can limit the production of NO, which has been shown to predominantly act as an inducer of apoptosis (42).

The results of the present study demonstrated that NM potently inhibited tumor growth and enhanced the expression of ECM proteins in female nude mice with HeLa xenografts, suggesting the therapeutic value of this specific nutrient complex in the treatment of cervical cancer. Supplementation with NM has beneficial effects in optimizing the basement membrane by increasing the stability and thickness of collagen IV, collagen I and the glycoproteins supporting the matrix, such as laminin and fibronectin. Furthermore, the micronutrient mixture appears to be safe to use. In a previous in vivo study addressing safety, it was observed that administering NM at doses of 30, 90 or $150 \mathrm{mg} /$ day to adult female osteogenic disorder Shionogi (ODS) rats (weighing 250-300 g) for 7 days, had no adverse effects on vital organs (heart, liver and kidney). In addition, it did not adversely affect functional serum enzymes, indicating that the NM is safe to use even at these high doses, which far exceed the normal equivalent dosage of the nutrient (43). 


\section{Acknowledgements}

This study was funded by Dr. Rath Health Foundation (Santa Clara, CA, USA), a non-profit organization. The authors would particularly like to thank Earl Rainey for maintenance of the animal colony.

\section{References}

1. Jemal A, Bray F, Center MM, Ferley J, Ward E and Forman D: Global cancer statistics. CA Cancer J Clin 61: 69-90, 2011.

2. American Cancer Society: Cervical cancer: What are the key statistics about cervical cancer? http://www.cancer.org/cancer/ cervicalcancer/detailedguide/cervical-cancer-key-statistics. Last revised January 31, 2014. Accessed June 9, 2014.

3. Cancer.net: Cervical cancer: Statistics. http://www.cancer.net/ cancer-types/cervical-cancer/statistics. Last reviewed April 2014 Accessed June 9, 2014.

4. Fidler IJ: Molecular biology of cancer: Invasion and metastasis. In: Cancer Principles and Practice of Oncology, DeVita VT Jr, Hellman S and Rosenberg SA (eds). 5th edition. Lippincott-Raven, Philadelphia, PA, pp135-152, 1997.

5. Egeblad M and Werb Z: New functions for the matrix metalloproteinases in cancer progression. Nat Rev Cancer 2: 161-174, 2002.

6. Folkman J: Role of angiogenesis in tumor growth and metastasis. Semin Oncol 29 (Suppl 16): 15-18, 2002.

7. Chambers AF and Matrisian LM: Changing views on the role of matrix metalloproteinases in metastasis. J Natl Cancer Inst 89: 1260-1270, 1997

8. Kleiner DE and Stetler-Stevenson WG: Matrix metalloproteinases and metastasis. Cancer Chemother Pharmacol 43 (Suppl): 42-51, 1999.

9. Yurchenko PD and Schitny JC: Molecular architecture of basement membranes. FASEB J 4: 1577-1590, 1990.

10. Barsky SH, Siegel GP, Jannotta F and Liotta LA: Loss of basement membrane components by invasive tumors but not by their benign counterparts. Lab Invest 49: 140-147, 1983.

11. Liotta LA, Tryggvason K, Garbisa S, Hart I, Foltz CM and Shafie S: Metastatic potential correlates with enzymatic degradation of basement membrane collagen. Nature 284: 67-68, 1980.

12. Stetler-Stevenson WG: The role of matrix metalloproteinases in tumor invasion, metastasis and angiogenesis. Surg Oncol Clin N Am 10: 383-392, 2001.

13. Stetler-Stevenson WG: Type IV collagenases in tumor invasion and metastasis. Cancer Metastasis Rev 9: 289-303, 1990.

14. Davidson B, Goldberg I, Koplovic J, Lerner-Geva L, Gottlieb WH, Weiss B, Ben-Baruch G and Reich R: Expression of matrix metalloproteinase-9 in squamous cell carcinoma of the uterine cervix - clinicopathologic study using immunohistochemistry and mRNA in situ hybridization. Gynecol Oncol 72: 380-386, 1999.

15. Rath M and Pauling L: Plasmin-induced proteolysis and the role of apoprotein (a), lysine and synthetic analogs. J Orthomol Med 7 : $17-23,1992$.

16. Andreasen PA, Kjøller L, Christensen L and Duffy MJ: The urokinase-type plasminogen activator system in cancer metastasis: A review. Int J Cancer 72: 1-22, 1997.

17. Niedzwiecki A, Roomi MW, Kalinovsky T and Rath M: Micronutrient synergy - a new tool in effective control of metastasis and other key mechanisms of cancer. Cancer Metastasis Rev 29: 529-543, 2010.

18. Roomi MW, Kalinovsky T, Rath $\mathrm{M}$ and Niedzwiecki A Modulation of u-PA, MMPs and their inhibitors by a nove nutrient mixture in human female cancer cell lines. Oncol Rep 28: 768-776, 2012.

19. Roomi MW, Ivanov V, Kalinovsky T, Niedzwiecki A and Rath M: Suppression of human cervical cancer cell lines Hela and DoTc2 4510 by a mixture of lysine, proline, ascorbic acid and green tea extract. Int J Gynecol Cancer 16: 1241-1247, 2006.

20. Cameron E, Pauling L and Leibovitz B: Ascorbic acid and cancer: A review. Cancer Res 39: 663-681, 1979.

21. Almholt K, Juncker-Jensen A, Laerum OD, Danø K, JohnsenM, Lund LR and Rømer J: Metastasis is strongly reduced by the matrix metalloproteinase inhibitor Galardin in the MMTV-PymT transgenic breast cancer model. Mol Cancer Ther 7: 2758-2767, 2008 .
22. Pankov R and Yamada KM: Fibronectin at a glance. J Cell Sci 115: 3861-3863, 2002.

23. Ruoslahti E: Fibronectin and its integrin receptors in cancer. Adv Cancer Res 76: 1-20, 1999.

24. Timpl R, Rohde H, Robey PG, Rennard SI, Foidart JM and Martin GR: Laminin - a glycoprotein from basement membranes. J Biol Chem 254: 9933-9937, 1979.

25. Sun Z, Chen YH, Wang P, Zhang J, Gurewich V, Zhang P and Liu JN: The blockage of high-affinity lysine binding sites of plasminogen by EACA significantly inhibits prourokinase-induced plasminogen activation. Biochem Biophys Acta 1596: 182-192, 2002.

26. Valcic S, Timmermann BN, Alberts DS, Wachter GA, Krutzsch M, Wymer J and Guillén JM: Inhibitory effect of six green tea catechins and caffeine on the growth of four selected human tumor cell lines. Anticancer Drugs 7: 461-468, 1996.

27. Mukhtar H and Ahmed N: Tea polyphenols: Prevention of cancer and optimizing health. Am J Clin Nutr 71 (Suppl 6): 1698S-1702S, 2000.

28. Yang CY, Liao J, Kim K, Yurtow EJ and Yang CS: Inhibition of growth and induction of apoptosis in human cancer cell lines by tea polyphenols. Carcinogenesis 19: 611-616 1998.

29. Taniguchi S, Fujiki H, Kobayashi H, Go H, Miyado K, Sadano H and Shimikawa R: Effect of (-) epigallocatechin gallate, the main constituent of green tea, on lung metastasis with mouse B16 melanoma cell lines. Cancer Lett 65: 51-54, 1992.

30. Hara Y: Green Tea - Health Benefits and Applications. Marcel Dekker, New York, NY, 2001.

31. Kawakami S, Kageyama Y, Fujii Y, Kihara K and Oshima H: Inhibitory effects of N-acetyl cysteine on invasion and MMP-9 production of T24 human bladder cancer cells. Anticancer Res 21: 213-219, 2001.

32. Morini M, Cai T, Aluigi MG, Noonan DM, Masiello L, De Floro S, D'Agostinin F, Albini A and Fassima G: The role of the thiol N-acetyl cysteine in the prevention of tumor invasion and angiogenesis. Int J Biol Markers 14: 268-271, 1999.

33. Yoon SO, Kim MM and Chung AS: Inhibitory effects of selenite on invasion of HT 1080 tumor cells. J Biol Chem 276: 20085-20092, 2001

34. Cha J, Roomi MW, Ivanov V, Kalinovsky T, Niedzwiecki A and Rath M: Ascorbate supplementation inhibits growth and metastasis of B16FO melanoma and 4T1 breast cancer cells in vitamin C deficient mice. Int J Oncol 42: 55-64, 2013.

35. Naidu KA, Karl RC, Naidu KA and Coppola D: Antiproliferative and proapoptotic effect of ascorbyl stearate in human pancreatic cancer cells: Association with decreased expression of insulin-like growth factor 1 receptor. Dig Dis Sci 48: 230-237, 2003.

36. Anthony HM and Schorah CJ: Severe hypovitaminosis $\mathrm{C}$ in lung-cancer patients: The utilization of vitamin $\mathrm{C}$ in surgical repair and lymphocyte-related host resistance. Br J Cancer 46: 354-367, 1982.

37. Maramag C, Menon M, Balaji KC, Reddy PG and Laxmanan S: Effect of vitamin $C$ on prostate cancer cells in vitro: effect on cell number, viability and DNA synthesis. Prostate 32: 188-195, 1997.

38. Koh WS, Lee SJ, Lee H, Park C, Park MH, Kim WS, Yoon SS, Park K, Hong SI, Chung MH and Park CH: Differential effects and transport kinetics of ascorbate derivatives in leukemic cell lines. Anticancer Res 8: 2487-2493, 1998.

39. Chen Q, Espey MG, Krishna MC, Mitchell JB, Corpe CP, Buettner GR, Shacter E and Levine M: Pharmacologic ascorbic acid concentrations selectively kill cancer cells: Action as a pro-drug to deliver hydrogen peroxide to tissues. Proc Natl Acad Sci USA 102: 13604-13609, 2005.

40. Núñez Martín C and Ortiz de Apodaca y Ruiz A: Ascorbic acid in the plasma and blood cells of women with breast cancer. The effect of consumption of food with an elevated content of this vitamin. Nutr Hosp 10: 368-372, 1995.

41. Kurbacher CM, Wagner U, Kolster B, Andreotti PE, Krebs D and Bruckner HW: Ascorbic acid (vitamin C) improves the antineoplastic activity of doxorubicin, cisplatin and paclitaxel in human breast carcinoma cells in vitro. Cancer Lett 103: 183-189, 1996.

42. Cooke JP and Dzau VJ: Nitric oxide synthase: Role in the genesis of vascular disease. Annu Rev Med 48: 489-509, 1997.

43. Roomi MW, Ivanov V, Netke S, Niedzwiecki A and Rath M: Serum markers of the liver, heart and kidney and lipid profile and histopathology in ODS rats treated with nutrient synergy. J Am Coll Nutr 22: 477, 2003. 